\title{
When Place Matters: Shuttling of Enolase-1 Across Cellular Compartments
}

\author{
Miroslava Didiasova $^{1 *}$, Liliana Schaefer ${ }^{2}$ and Malgorzata Wygrecka ${ }^{1,3}$ \\ ' Department of Biochemistry, Faculty of Medicine, Universities of Giessen and Marburg Lung Center, Giessen, Germany, \\ ${ }^{2}$ Institute of Pharmacology and Toxicology, Goethe University Frankfurt, Frankfurt, Germany, ${ }^{3}$ Member of the German \\ Center for Lung Research, Giessen, Germany
}

\section{OPEN ACCESS}

Edited by:

Randall Glenn Worth,

The University of Toledo,

United States

Reviewed by:

Gotam Kumar Jarori,

Tata Institute of Fundamental

Research, India

Jadwiga Pietkiewicz,

Wrocław Medical University, Poland

*Correspondence:

Miroslava Didiasova miroslava.didiasova@biochemie.

med.uni-giessen.de

Specialty section:

This article was submitted to

Molecular Medicine,

a section of the journal

Frontiers in Cell and Developmental

Biology

Received: 29 January 2019

Accepted: 05 April 2019

Published: 26 April 2019

Citation:

Didiasova M, Schaefer $L$ and Wygrecka M (2019) When Place Matters: Shuttling of Enolase-1 Across Cellular Compartments.

Front. Cell Dev. Biol. 7:61 doi: 10.3389/fcell.2019.00061
Enolase is a glycolytic enzyme, which catalyzes the inter-conversion of 2-phosphoglycerate to phosphoenolpyruvate. Altered expression of this enzyme is frequently observed in cancer and accounts for the Warburg effect, an adaptive response of tumor cells to hypoxia. In addition to its catalytic function, ENO-1 exhibits other activities, which strongly depend on its cellular and extracellular localization. For example, the association of ENO-1 with mitochondria membrane was found to be important for the stability of the mitochondrial membrane, and ENO-1 sequestration on the cell surface was crucial for plasmin-mediated pericellular proteolysis. The latter activity of ENO-1 enables many pathogens but also immune and cancer cells to invade the tissue, leading further to infection, inflammation or metastasis formation. The ability of ENO-1 to conduct so many diverse processes is reflected by its contribution to a high number of pathologies, including type 2 diabetes, cardiovascular hypertrophy, fungal and bacterial infections, cancer, systemic lupus erythematosus, hepatic fibrosis, Alzheimer's disease, rheumatoid arthritis, and systemic sclerosis. These unexpected non-catalytic functions of ENO-1 and their contributions to diseases are the subjects of this review.

Keywords: enolase-1, multitasking protein, glycolysis, protein compartmentalization, cancer

\section{INTRODUCTION}

Enolase is a metalloenzyme that catalyzes the inter-conversion of 2-phosphoglycerate to phosphoenolpyruvate within glycolysis. This enzymatic reaction is reversible and depends on the concentration of the substrates available in the environment (Wold and Ballou, 1957a,b). Three isotypes of this enzyme have been described in mammals thus far: $\alpha$-enolase (ENO-1), ubiquitously expressed in most of the tissues, $\beta$-enolase (ENO-3), expressed primary in muscle tissue and $\gamma$-enolase (ENO-2), present mostly in neural tissues. All three isotypes form homo-dimers utilizing two magnesium ions non-covalently bound to the active site (Marangos et al., 1978; Brewer, 1981; Pancholi, 2001). In general, glycolytic enzymes are evolutionary highly conserved proteins, exhibiting up to $40-90 \%$ amino acid sequence homology among species (Pancholi, 2001). Although most of the glycolytic enzymes could be considered as housekeeping proteins, expression of ENO-1 has been found to dramatically vary depending on the pathological, stress, or metabolic state of the cell. This ENO-1 characteristic has been highlighted in a retrospective study analyzing 169 
articles published in the field of proteomics between 2004 and 2006. The authors of this report demonstrated that ENO-1 is the most differentially expressed protein in humans regardless of a tissue type and a pathological condition (Petrak et al., 2008). Consequently, several pathologies with distinct etiologies reported disturbed expression and/or activity of this enzyme. For instance, altered levels of ENO-1 has been demonstrated in Alzheimer's disease (Castegna et al., 2002; Butterfield and Lange, 2009; Owen et al., 2009), rheumatoid arthritis (Kinloch et al., 2005; Montes et al., 2011), systemic sclerosis (Terrier et al., 2010; Mehra et al., 2013), type 2 diabetes (Li et al., 2013, 2015), systemic lupus erythematosus (Hawro et al., 2015; Li et al., 2018), hepatic fibrosis (Peng et al., 2013; Zhang et al., 2013), and fungal and bacterial infections (Bergmann et al., 2013; Funk et al., 2016; Ji et al., 2016). In addition, ENO-1 has been found to be overexpressed in more than 20 types of human cancer (Altenberg and Greulich, 2004). This finding can be partially explained by the Warburg effect (Vander Heiden et al., 2009), a process, in which cancer cells switch from oxidative phosphorylation to anaerobic glycolysis under hypoxic conditions. However, recent observations have brought interest on the non-catalytic functions of ENO-1 (Pancholi, 2001; Diaz-Ramos et al., 2012; Ji et al., 2016). This glycolytic enzyme (primary localized in the cytoplasm) has been detected at different unexpected sites of the cell, driving such diverse processes as plasminogen binding, maintenance of the mitochondrial membrane stability, RNA chaperone activity and signal transduction. The latter has been found to be associated with the release of ENO-1 to the extracellular space.

The ability of ENO-1 to execute more than one function, depending on its cellular localization, opened the door for ENO-1 to the family of the moonlighting proteins. These unexpected functions of ENO-1 will be discussed in this review.

\section{ENO-1 Function in Cytoplasm}

The primary function of ENO-1 is its catalytic contribution to glycolysis in the cytoplasm. For the detailed biochemical course of this reaction please refer to Qin et al. (2012). Although ENO-1 catalyzes the semi-final step of glycolysis, this enzyme desires more then just an ordinary membership in the long list of glycolytic enzymes. A study by Capello et al. (2016), revealed that silencing of ENO-1 has a dramatic impact on the overall metabolic state of the cell. Proteomic profiling of human pancreatic cancer cells demonstrated that ENO-1 knockdown induces a metabolic shift in these cells. Specifically, ENO-1 silencing promoted $\beta$-oxidation of fatty acids, amino acid catabolism, and nucleotide base synthesis. Furthermore, ENO-1 depleted cancer cells evaded the "glycolytic shutoff" by enhancing mitochondrial electron flux followed by increased oxygen consumption, thus restoring oxidative phosphorylation. A functional consequence of these alterations has been observed both, in vitro and in vivo as ENO-1 depleted cancer cells exhibited decreased growth, survival and clonogenic ability (Capello et al., 2016). Thus, this study highlighs the key role of ENO-1 in the regulation of the Warburg effect in cancer cells. Besides the role of ENO-1 in metabolic shift of cancer cells, ENO-1 may also regulate metabolic processes in other cell types, including pulmonary artery smooth muscle cells (PASMCs) (Dai et al., 2018).
Dai et al. (2018), showed that silencing of ENO-1 inhibited hypoxia-induced glycolysis and restored basal respiration and oxygen consumption rate accompanied by increased $\beta$-oxidation and glutamine consumption in PASMC. In addition, loss of ENO-1 reduced PASMC proliferation and de-differentiation and induced cell apoptosis in a AMPK-Akt-dependent manner. Consequently, blockage of ENO-1 reversed hypoxia and/or Sugen 5416-induced pulmonary hypertension $(\mathrm{PH})$ in rats. Importantly, these effects of ENO-1 were independent of its catalytic activity as phosphoenolpyruvate, the product of the reaction catalyzed by ENO-1, failed to reverse effects of ENO-1 depletion (Dai et al., 2018).

Furthermore, ENO-1 inhibition turned out to be also beneficial in type 2 diabetes. Type 2 diabetes mellitus is a metabolic disorder characterized by hyperglycemia and insulin resistance. Moreover, it is associated with the obesity and the development of secondary comorbidities, such as liver, kidney, and heart disorders. Interestingly, in an experimental murine model of type 2 diabetes mellitus, inhibition of ENO-1 by the ENOblock reduced blood glucose concentration and LDL cholesterol levels as well as decreased secondary diabetic complications such as adipocyte size, cardiac hypertrophy, expression of inflammatory mediators and attenuated liver fibrosis (Jung et al., 2013; Cho et al., 2017). The ENOblock is a non-substrate cell permeable ENO-1 inhibitor that was originally discovered in a small molecule screening in cancer cell cytotoxicity assays (Jung et al., 2013). These assays help to detect agents that prefentially kill hypoxic cancer cells, thus the cells, which are mainly responsible for the resistance to anti-cancer therapies. Accordingly, ENOblock succesfully decreased migration and invasion of human colon carcinoma cells and inhibited cancer cell dissemination in a zebrafish tumor xenograft model. In addition, ENOblock was found to potentiate the action of the anti-cancer drugs such as taxol and vincristine (Jung et al., 2013).

Cytoplasmic ENO was found to function as a stress-related or as a heat-shock protein. This property of ENO has been described in bacteria, yeasts, parasites, and mammalian cells. For instance, ENO was identified as one of the proteins being overexpressed under acidic conditions in Streptococcus mutants (S. mutants), suggesting that ENO may participate in the survival and proliferation of S. mutans in low pH (Wilkins et al., 2002). In Escherichia coli (E. coli), ENO was found to be a major target of stress-inducing oxidative agents (Tamarit et al., 1998), whereas in yeasts, ENO-2 was resported to function as a heat shock protein induced by elevated temperature (Iida and Yahara, 1985). Parasites seem to utilize a similar mechanisms in order to overcome stress conditions. Namely, in Plasmodium falciparum (P. falciparum), ENO was found to bind to endoprotease (DegP), an enzyme, which plays important role in thermal and oxidative resistance (Sharma et al., 2014). Lastly, findings in cardiomyocytes resemble those obtained in bacteria, yeasts, and parasites. Specifically, the interaction of ENO-1 with heat shock protein 70 was shown to protect cardiomyocytes against oxidative stress (Luo et al., 2011). These results indicate that the stress-related function of ENO is conserved among different species. Besides, ENO-1 was reported to regulate the dynamics 
of the cytoskeletal filaments. In particular, it has been shown that ENO-1 may interact with tubulin and microtubules during myogenesis (Keller et al., 2007). In addition, ENO-1 can be "activated" upon stress conditions and interact with contractile filaments in cardiomyocytes thus inducing their contraction in a extracellular signal-regulated kinase (ERK) 1/2-dependent manner (Mizukami et al., 2004). Finally, ENO-1 has been detected in the centrosome of HeLa cells during the cell cycle. Although not experimentally proven, it is conceivable, that centrosomal ENO-1 may regulate the interphase cytoskeleton and the mitotic spindle organization (Johnstone et al., 1992).

Altogether, these findings indicate that, cytosolic ENO-1 irrespective of its catalytic function, contributes to the diverse physiological and pathological conditions (Figure 1).

\section{Nuclear Activities of ENO}

By using an alternative start codon, ENO-1 gene can give rise to a truncated $37 \mathrm{kDa}$ protein, also called myc promoter-binding protein 1 (MBP-1), which is primary localized in the nucleus. MBP-1 lack's the first 96 amino acids present in ENO-1 (Subramanian and Miller, 2000) and its primary function is to bind and suppresses the activity of c-myc transcription factor. In detail, MBP-1 recognizes TATA motif in the minor groove of c-myc P2 promoter and negatively regulates its activity by preventing the formation of a transcription initiation complex (Feo et al., 2000; Subramanian and Miller, 2000). The c-myc proto-oncogene is the master regulator of cell proliferation, differentiation and apoptosis (Dang, 2013). Although, both MBP-1 and ENO-1 may bind to c-myc (Feo et al., 2000), only MBP-1 represses activity of this transcription factor and thus acts as a tumor suppressor.

Consequently, MBP-1 expression has been correlated with the clinicopathological features of diverse cancer types

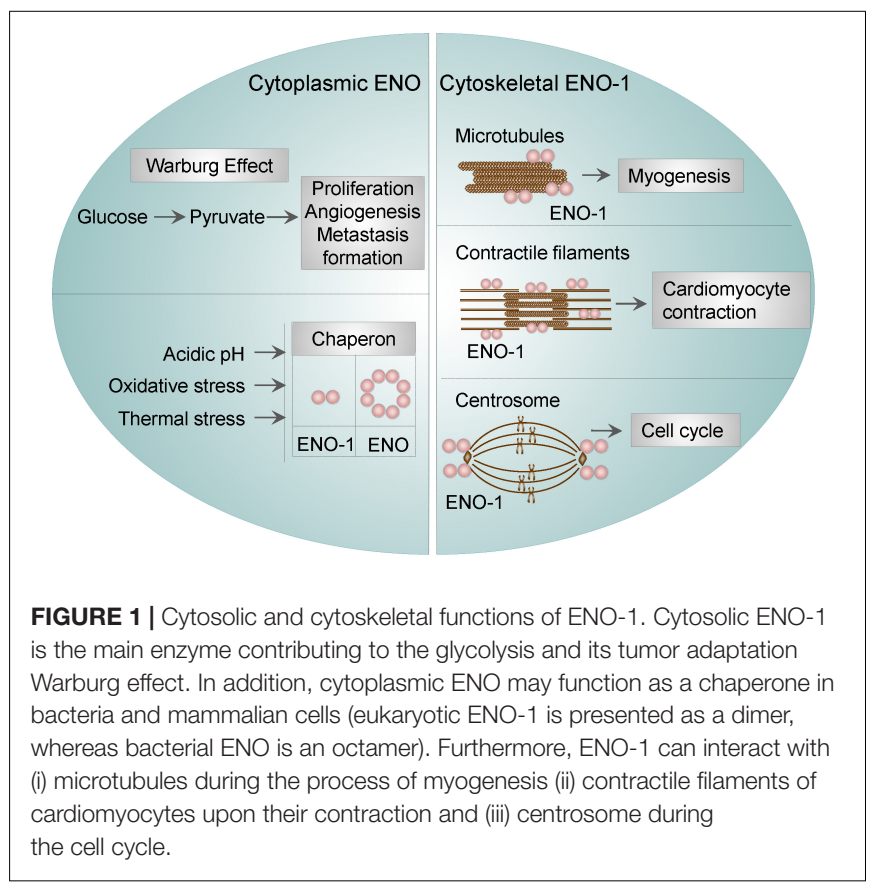

including breast, prostate, and gastric cancer. In vivo studies demonstrated that, ectopic overexpression of MBP-1 inhibits proliferation, migration, and invasion of cancer cells (Ray et al., 1995; Ghosh et al., 2005a,b; Hsu et al., 2009; Kanda et al., 2009). For instance, Hsu et al. (2009) reported, that MBP-1 suppresses epithelial-mesenchymal transition (EMT) by inhibiting COX-2 expression in gastric cancer. In addition, reduction of cyclin D1 and myocyte-specific enhancer factor 2C (MEF2C) transcriptional activity in prostate cancer cells was noted (Ghosh et al., 2005a). Tumor suppressor activities of MBP-1 have been also observed in different types of human breast carcinomas (Lo Presti et al., 2010). While the majority of breast carcinomas displayed increased ENO-1 levels, the levels of MBP-1 were reduced with a concomitant increased in the activity of c-myc. Loss of MBP-1 expression predicted local recurrence of breast cancer, while its expression correlated with a $92 \%$ local recurrence-free survival. No correlation between nuclear MBP-1 expression and cytoplasmic ENO-1 levels was described, suggesting that the expression of MBP-1 is regulated independently from ENO-1 (Lo Presti et al., 2010).

Although the mechanisms regulating MBP-1/ENO-1 ratio are not fully understood, several factors such as hypoxia, ER stress and glucose concentrations were described to influence MBP-1 and ENO-1 transcription. It is well-recognized that sustained hypoxia in growing tumors can enhance the invasiveness of cancer cells by regulating c-myc expression (Huang, 2008). Although ENO-1 gene gives rise to both, ENO-1 and MBP-1, ENO-1 seems to be preferentially translated upon hypoxia (Sedoris et al., 2010), whereas MBP-1 in response to ER stress (Sedoris et al., 2010; Maranto et al., 2015). Moreover, alterations in the glucose concentration may influence the MBP-1/ENO-1 ratio. Breast cancer cells grown at a physiological or a high concentration of glucose demonstrate increased proliferation with a corresponding decrease in the MBP- 1 levels (Sedoris et al., 2007). In contrast, the cells grown at a low concentration of glucose display elevated amounts of MBP-1. In addition to the translational regulation of MBP-1, its interactions with different protein partners may influence its association with the c-myc promoter. For example, the binding of the Kelch protein NS1-BP to MBP-1 was reported to enhance MBP-1-mediated repression of c-myc in vitro and in vivo (Perconti et al., 2007). Also, Notch 1 receptor intracellular domain (N1IC) was found to associate with MBP-1 as well as with ENO-1. It is known, that N1IC forms a complex with a YY1 transcription factor to activate c-myc. However, binding of both ENO-1 and MBP-1 to N1IC, suppressed N1IC-mediated c-myc transcriptional activity leading to reduced colony-forming ability of human erythroleukemia K562 cells (Hsu et al., 2008). Nuclear activities of ENO have been also detected in plants, in particular, in Arabidopsis thaliana. Findings by Lee et al. (2002) demonstrated, that LOS2, a genetic locus required for cold-responsive gene transcription, encodes ENO. Los2 protein binds to the promoter of the STZ/ZAT10 gene, which contains the cold- and osmotic stress-responsive elements and possesses similarities to the MBP1-binding sequence in the human c-myc promoter. Interestingly, Los2 also binds to the DNA probe containing the human MBP-1-binding site in the 
c-myc promoter, indicating that the plant ENO may function as a transcription factor (Lee et al., 2002).

To sum up, the results mentioned above demonstrate that MBP-1 is a potent tumor-suppressor (Figure 2) and thus a promising target for anti-cancer therapies. Accordingly, a recent study by Cho et al. (2017) reported that, ENOblock induces MBP-1 nuclear localization consequently leading to the decreased expression of $\mathrm{c}$-myc. This resulted in a decreased migration and invasion of human colon carcinoma cells and finally their death (Jung et al., 2013). Future clinical studies will clarify whether this inhibitor may have beneficial effects in cancer or diabetes patients.

\section{Association of ENO With Mitochondria}

Association of ENO with mitochondria was first described in Arabidopsis thaliana cells (Giege et al., 2003). Few years later, Entelis et al. (2006) observed a similar effect in yeasts. Namely, ENO-2 and to a lesser extent ENO-1 were found to be tightly bound to the mitochondrial membrane and possessed RNA binding activity (Brandina et al., 2006; Entelis et al., 2006) thus facilitating the import of cytosolic tRNA into mitochondria. As mitochondrial DNA carries information for a small number of macromolecules, there is a constant need for a supply of proteins and RNAs from nucleo-cytoplasmic compartment. In yeasts, two nuclear DNA-encoded tRNAs are targeted to mitochondria: tRK1 (tRNA ${ }^{\text {Lys }} \mathrm{CUU}$ ) (Martin et al., 1979) and tRNA $^{\text {Gln }}$ (Rinehart et al., 2005). The transport of tRK1 is highly specific and requires interaction with the precursor of mitochondrial lysyl-tRNA synthetase (preMsk1p) (Tarassov et al., 1995a,b). However, the interaction of tRK1 with preMsk1p

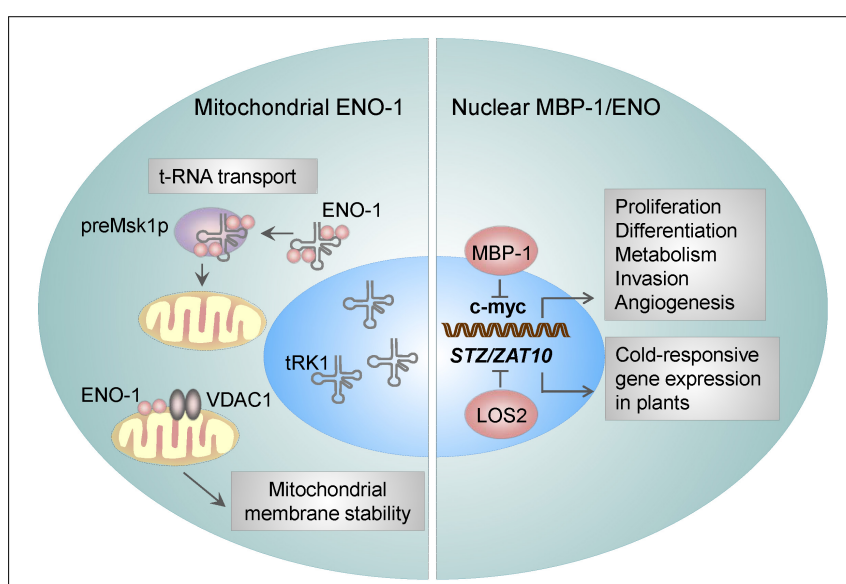

FIGURE 2 | ENO-1 activities in the nucleus and mitochondria. Mitochondria bound ENO-1 acts as a RNA chaperone by binding to and transporting nucleo-cytoplasmic tRNAs to the mitochondria. Furthermore, by binding to the VDAC1 (an integral mitochondrial membrane protein), ENO-1 participates in the stabilization of the mitochondrial membrane potential. By using an alternative start codon, ENO-1 gene can give rise to truncated $37 \mathrm{kDa}$ protein - myc promoter-binding protein 1 (MBP-1), which suppresses the activity of c-myc transcription factor and thereby regulates proliferation and invasion of cancer cells. ENO in plants is encoded by LOS2, which binds to the promoter of the STZ/ZAT10 gene, that possesses the cold- and osmotic stress-responsive elements. is not sufficient for the transport of tRK1 to mitochondria. Unexpectedly, ENO-2 and ENO-1 have been identified to bind tRK1, enhance tRK1-preMsk1p complex formation and to mediate tRK1 transport to this organelle (Figure 2) (Brandina et al., 2006; Entelis et al., 2006). While the yeast ENO-2 preferentially binds to tRK1, in humans all ENO isoforms may interact with tRK1 and facilitate its transport to mitochondria (Baleva et al., 2015). Interestingly, other glycolytic enzymes, including 3-phospho-glycerate kinase, hexokinase, pyruvate kinase, and glyceraldehyde-3 phosphate dehydrogenase have been found to associate with the mitochondrial membrane too (Brandina et al., 2006). Although the binding of other glycolytic enzymes to mitochondria was found to be relatively weak, it was suggested that they enable direct transport of pyruvate to this organelle.

The functional importance of the above mentioned process has been highlighted during cardiac ischemia and hyperthrophy. Binding of ENO-1 to mitochondria was reported to dramatically decline in cardiomyocytes isolated from the hearts of doxorubicin (Dox)-treated rats (Gao et al., 2014). Doxorubicin is used in the treatment of the breast cancer, however its clinical use is limited as it causes severe side effects like mitochondrial damage in cardiomyocytes and subsequent apoptosis of these cells (Carvalho et al., 2009). Mechanistically, mitochondria isolated from ENO-1 depleted cells display a higher sensitivity to $\mathrm{Ca}^{2+}$-induced membrane depolarization and permeabilization and thereby a severe mitochondria dysfunction. This effect can be restored by the addition of the recombinant ENO-1 to the isolated mitochondria, which prevents mitochondrial membrane permeabilization and subsequent organelle fragmentation (Gao et al., 2014). These findings suggest that ENO-1 exerts a protective effect on cardiomyocytes during myocardial injury by stabilizing the mitochondrial membrane potential. Accordingly, further studies revealed that ENO-1 interacts with VDAC1 (Figure 2), an integral membrane protein, which is a critical regulator of mitochondrial membrane stability (Gao et al., 2014).

Although binding of ENO-1 to mitochondria seems to prevent $\mathrm{Ca}^{2+}$-induced mitochondrial dysfunction in an isolated system, the concomitant increase of ENO-1 in the cytosol of cardiomyocytes observed upon Dox-treatment of rats was found to be rather harmful. Gao et al. (2015), demonstrated that silencing of ENO-1 in the hearts of rats prevents Dox-induced heart injury and cardiomyocyte apoptosis. This effect was also confirmed in cultured cardiomyocytes and was independent of ENO-1's catalytic activity. Thus the relationship between ENO-1 and mitochondria in Dox-induced cardiotoxicity is more complex. At one site, association of ENO-1 with mitochondria is protective since it prevents organelle permeabilization in the isolated system. On the other hand, the concomitant increase of the cytosolic ENO-1 after Dox treatment observed in vivo is harmful and potentiates Dox-induced heart injury. These contrary results highlight compartment-specific functions of ENO-1.

\section{ENO in Intracellular Vesicles}

Vacuoles present in parasites, yeast and plants are functional equivalents of the mammalian lysosomes. Transport of different 
molecules between cytosol and vacuole is crucial for many physiological processes including, ion homeostasis, storage of various molecules, detoxification, proteolysis of cytosolic and membrane proteins (Rotin et al., 2000) and turnover of organelles (Kim et al., 2007). Intriguingly, ENO has been recognized as a constituent and as a regulator of vacuoles. For example, in $P$. falciparum, ENO was found to associate with a food vacuole (Bhowmick et al., 2009). Another study identified three different variants of ENO present in this organelle; the typical $50 \mathrm{kDa}$ form and the 65 and $75 \mathrm{kDa}$ forms, the latters were shown to be ubiquitinated. While the low molecular weight forms were reported to assist in the fusion of the food vacuoles, the $75 \mathrm{kDa}$ form of ENO was described to interact with hemozoin, a disposal product formed by the digestion of hemoglobin in blood-feeding parasites (Figure 3). Breakdown of hemoglobin leads to the release of high quantities of free heme, which is toxic to parasites. However, parasites may convert free heme to the non-toxic hemozoin and store it in vacuoles. Neutralization of the toxic heme by parasite specific enzymes is one of the mechanism by which parasites escape host immunity and survive in a hostile environment. Thus, it was suggested that different variants of ENO present in vacuoles may have distinct functional activities (Shevade et al., 2013). Experiments performed in yeasts described similar effects. Proteome profiling of the yeast vacuolar membrane identified ENO-2 to be enriched in this compartment, implying a possible transporter or fusion-related function (Wiederhold et al., 2009). Indeed, a study by Decker and colleagues revealed, that in Saccharomyces cerevisiae, ENO-1 and ENO-2 stimulate fusion of vacuoles independently from their catalytic functions (Figure 3). Consequently, deletion of either
ENO-1 or ENO-2 caused vacuole fragmentation. Furthermore, ENO-1 or ENO-2 deficiency prevented normal protein sorting to vacuoles, thus exacerbating the fusion defect (Decker and Wickner, 2006). Finally, the association of ENO with vacuoles has been also observed in plants. Barkla et al. (2009) demonstrated that ENO together with aldolase associate with subunits of the vacuolar $\mathrm{H}^{+}$-ATPase and $\mathrm{V}$-ATPase and stimulate $\mathrm{V}$-ATPase activity in vitro by increasing the affinity for ATP (Figure 3). Consistently, a single point mutation in the $5^{\prime}$ region of the ENO gene (los2 mutation), displayed increased sensitivity to salt and an impaired ability to regulate V-ATPase hydrolytic activity in response to aldolase. Furthermore, it was suggested that, ENO not only channels ATP to the V-ATPase, but also directly enhances $\mathrm{H}^{+}$-pump's activity (Barkla et al., 2009). Whether ENO-1 associates with lysosomes in mammalian cells requires further investigations.

\section{ENO Activities on the Membrane and in Extracellular Space}

Next unanticipated location of ENO-1 is cell surface and extracellular space, where ENO-1 either associates with exosomes or is secreted as a soluble protein. Cell surface bound ENO-1 has been detected on several cell types including immune (Miles et al., 1991; Redlitz et al., 1995; Wygrecka et al., 2009), cancer (Didiasova et al., 2014, 2015) and neuronal cells (Haque et al., 2018) as well as bacteria (Pancholi and Fischetti, 1998; Derbise et al., 2004). Outside of the cell, ENO-1 acts as a plasminogen binding receptor (PLG-R) (Figure 4) (Plow and Das, 2009). Plasminogen (PLG) is a zymogen, which is converted to the serine

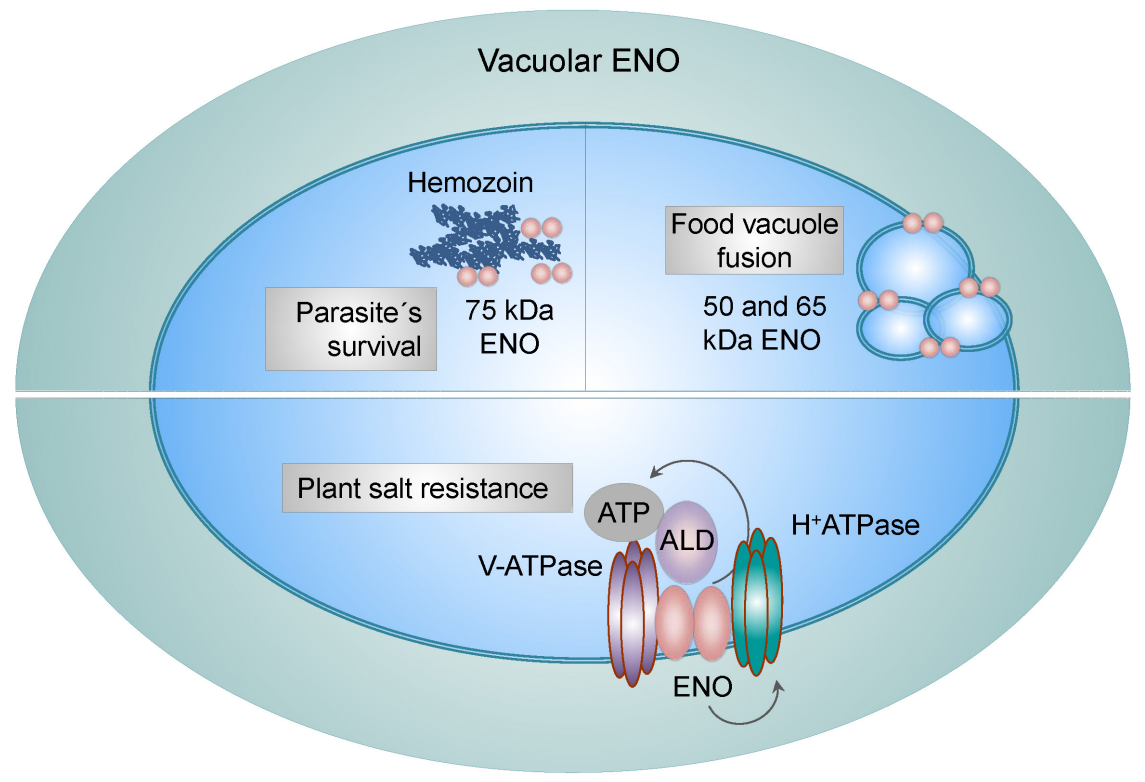

FIGURE 3 | Vacuole-related functions of ENO. Vacuole-associated ENO in parasites exists in three different variants: the low (50 and 65 kDa) and high ( 75 kDa) molecular weight forms. While the low molecular weight ENO variants regulate fusion of food vacuoles, the $75 \mathrm{kDa}$ form interacts with hemozoin, a disposal product of hemoglobin digestion. Binding of ENO to hemozoin plays a role in parasites survival. In plants, ENO binds to subunits of the vacuolar $\mathrm{H}^{+}$-ATPase and $\mathrm{V}$-ATPase and stimulates V-ATPase activity in an aldolase (ALD)-dependent manner by increasing the affinity for ATP. This mechanism is used by plants to overcome high salt concentrations. 


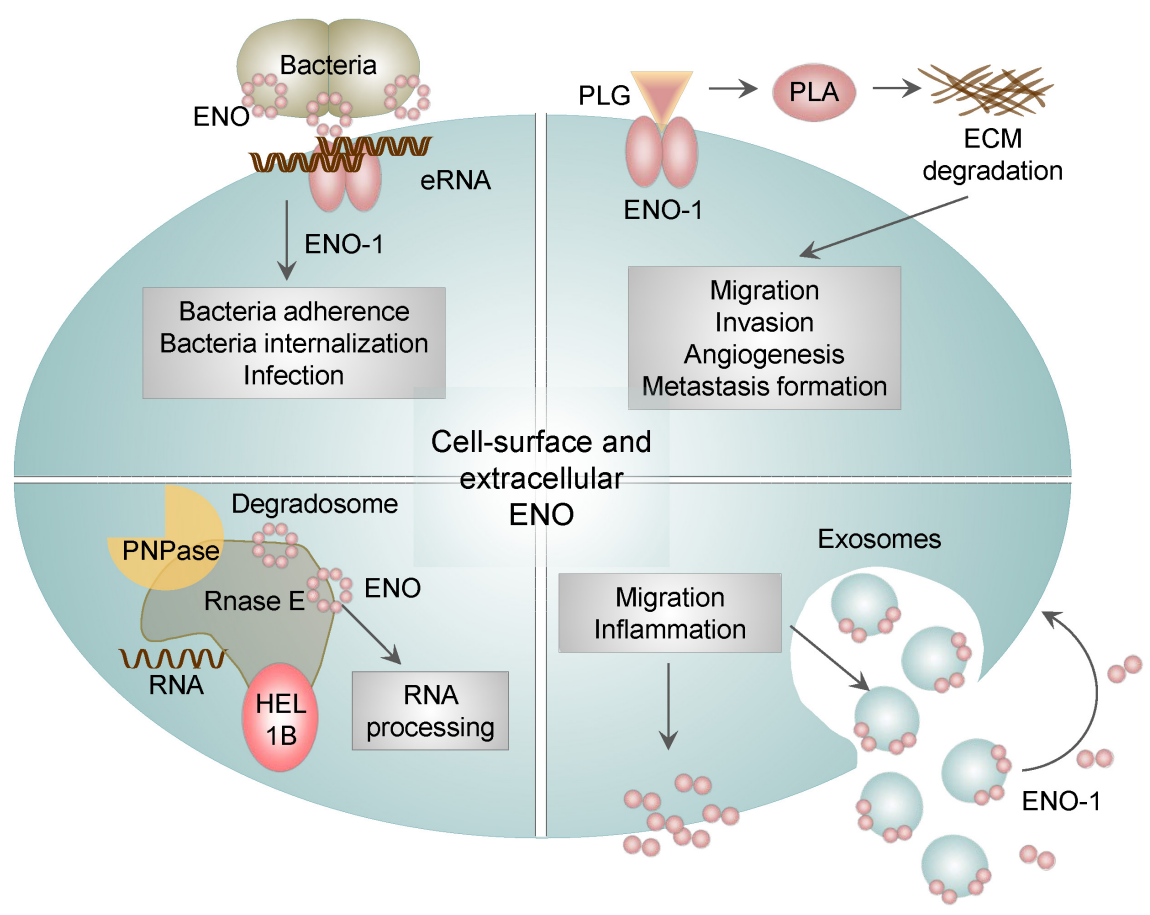

FIGURE 4 | The role of membrane bound and extracellular ENO. In addition to the intracellular activities, ENO-1 may be translocated to the cell surface or released into the extracellular environment as a free soluble protein or bound to exosomes. Surface bound ENO-1 acts as a plasminogen (PLG) binding receptor and participates in plasmin (PLA) formation, which degrades extracellular matrix proteins (ECM). Furthermore, cell surface ENO-1 can bind extracellular RNA (eRNA), which may act as a bridging molecule between bacterial ENO and eukaryotic ENO-1 and thus facilitate bacterial dissemination. In addition, ENO is a part of the bacterial degradosome, which consists of RNase E, RNA helicase 1B (HEL1B) and polynucleotide phosphorylase (PNPase). ENO binding to the degradosome affects the activity of the complex and consequently cellular RNA processing. Lastly, ENO-1 secreted outside of the cell either in the form of exosomes or as a free floating protein may induce migration and a pro-inflammatory phenotype of immune cells.

protease plasmin (PLA) in the presence of the physiological activators: urokinase-type PLG activator (uPA) or tissue-type PLG activator (tPA) (Didiasova et al., 2014). Consequently, PLA activates collagenases, degrades fibrin and several other matrix proteins. ENO-1-dependent PLA formation allows pathogens (Chhatwal, 2002) as well as immune (Wygrecka et al., 2009) and cancer cells (Hsiao et al., 2013) to invade tissue, consequently leading to infection, inflammation, and metastasis formation.

We previously demonstrated that pericellular proteolysis mediated by ENO-1 plays a crucial role during the recruitment of monocytes to the inflamed lung. Overexpression studies revealed that ENO-1 potentiated migration and matrix-penetrating capacity of monocytes in a PLA-dependent manner while monocytes bearing truncated ENO-1 variant missing PLG-binding site failed to infiltrate the lung (Wygrecka et al., 2009). Similar effects have been observed in the kidney stone disease, where cell surface bound ENO-1 enhanced migration and invasion of monocytes through renal interstitium (Chiangjong and Thongboonkerd, 2016).

On the cell surface of cancer cells, ENO-1 was reported to regulate migration, invasion and colony formation (Mikuriya et al., 2007; Cappello et al., 2009; Hsiao et al., 2013; Didiasova et al., 2015; Principe et al., 2015). In lung cancer, knock down of ENO-1 decreased the pericellular fibrinolytic activity of cancer cells and thereby their invasion. Consequently, adoptive transfer of an anti-ENO-1 antibody inhibited the formation of tumor metastasis in the lung and the bones (Hsiao et al., 2013). In breast cancer, increased levels of cell surface ENO-1 correlated with enhanced migration and invasion of cancer cells and these effects where abrogated by a specific peptide blocking PLG binding to ENO-1 (Didiasova et al., 2015).

The presence of ENO on the surface of bacteria has been shown to facilitate their migration and tissue invasion leading to the efficient dissemination of bacteria (Figure 3). This mechanism was found to be used by many bacteria including, S. pneumoniae (Bergmann et al., 2001, 2013), Borrelia spp. (Floden et al., 2011), Aeromonas hydrophila (Sha et al., 2009), Neisseria spp. (Knaust et al., 2007), Mycoplasma spp. (Bao et al., 2014) and by pathogenic fungi such as Paracoccidioides brasiliensis (Nogueira et al., 2010), Aspergillus fumigatus (Funk et al., 2016), Candida albicans (Funk et al., 2016), Pneumocystis carinii (Fox and Smulian, 2001) as well as parasites, such as Leishmania spp. (Vanegas et al., 2007), Trypanosoma spp. (Almeida et al., 2004), and Plasmodium spp. (Pal-Bhowmick et al., 2007a,b; Dutta et al., 2015, 2018). Interestingly, we reported that ENO localized on bacterial surface has an additional function to its PLG binding ability. Namely, ENO present on S. pneumoniae binds extracellular RNA (eRNA). Extracellular RNA is released from injured cells during infection, it associates on the one hand with ENO present on bacteria and on the other hand 
with ENO-1 localized on eukaryotic cells thereby facilitating infection of lung epithelial cells. Pretreatment of lung epithelial cells with RNase1 decreases not only the number of adherent bacteria but also the infection of host cells (Zakrzewicz et al., 2016). Taken together our results indicate that upon bacterial infection, eRNA serves as a "bridging molecule" between bacterial ENO and eukaryotic ENO-1 and thereby facilitates pathogen dissemination (Figure 4).

Intriguingly, the membrane-associated ENO in bacteria displays another moonlighting function. Namely, it is involved in the processing of rRNA and degradation of mRNA, and comprises a part of a larger complex termed degradosome. Degradosome is tightly anchored to the inner cytoplasmic membrane of bacteria and is additionally composed of RNA helicase 1B, RNase E, and polynucleotide phosphorylase (PNPase) (Liou et al., 2001). Disruption of the ENO binding to degradosome induces hypoactivity of the complex, which in turn leads to the reduced turnover of cellular RNA (Leroy et al., 2002). In addition, the degradosome-bound ENO was described to play a role in the regulation of the ptsG mRNA stability in E. coli. PtsG mRNA encodes the major glucose transporter and is rapidly degraded upon accumulation of glucose-6-P and fructose-6-P in bacteria. Interestingly, deletion of ENO can restore reduced levels of ptsG mRNA, by prolonging ptsG mRNA stability. These results indicate that ENO-mediated regulation of ptsG mRNA stability may coordinate bacterial response to a metabolic stress (Morita et al., 2004).

Despite a large number of studies demonstrating the active role of cell surface bound ENO-1 in invasion of immune, cancer cells and bacteria, the molecular mechanism driving ENO-1 translocation to the cell surface remains unclear. The lack of a signal peptide within the ENO-1 sequence suggests that this protein uses a non-classical secretory pathway to exteriorize.
Furthermore, the transport of ENO-1 to the extracellular space was found to be regulated by a plethora of factors. It has been shown that inflammatory stimuli, growth factors, and cell death alter ENO-1 cell surface abundance, thereby increasing the complexity of compartment-specific functions of ENO-1.

Broad range of inflammatory stimuli has been shown to regulate cell surface expression of ENO-1. For instance, LPS potentiated ENO-1 exteriorization in monocytes (Wygrecka et al., 2009) and in cancer cells (Didiasova et al., 2015; Perconti et al., 2017). Stimulation of macrophages with IFN- $\gamma$ in combination with vitamin D3 (Das et al., 2007) as well as the treatment of cancer cells with CCL-2 or TNF- $\alpha$ (Didiasova et al., 2015) enhanced ENO-1 transport to the cell surface. Dead cells displayed higher PLG binding capacity in comparison to viable cells and this effect was a consequence of enhanced cell surface exposure of different PLG receptors, including ENO-1 (O'Mullane and Baker, 1999; Ucker et al., 2012). Finally, growth factors, like TGF- $\beta 1$ (Didiasova et al., 2015) and EGF (Perconti et al., 2017) enhanced extracellular transport of ENO-1 in cancer cells.

Though many stimuli have the ability to potentiate cell surface expression of ENO-1, little is known about the mechanisms and intracellular factors that are crucial for the translocation of this glycolytic enzyme from intra- to extracellular space. For example, it was demonstrated that fluctuations in the intracellular levels of calcium, post-translational modifications (PTMs) and interactions with other proteins are crucial for LPS-triggered ENO-1 translocation to the extracellular space. In particular, we showed that the calcium influx is a driving force for ENO-1 transport to the cell surface as well as to the extracellular milieu in the form of exosomes. The stromal interaction molecule (STIM) 1 and the calcium release-activated calcium modulator (ORAI) 1-mediated store-operated calcium

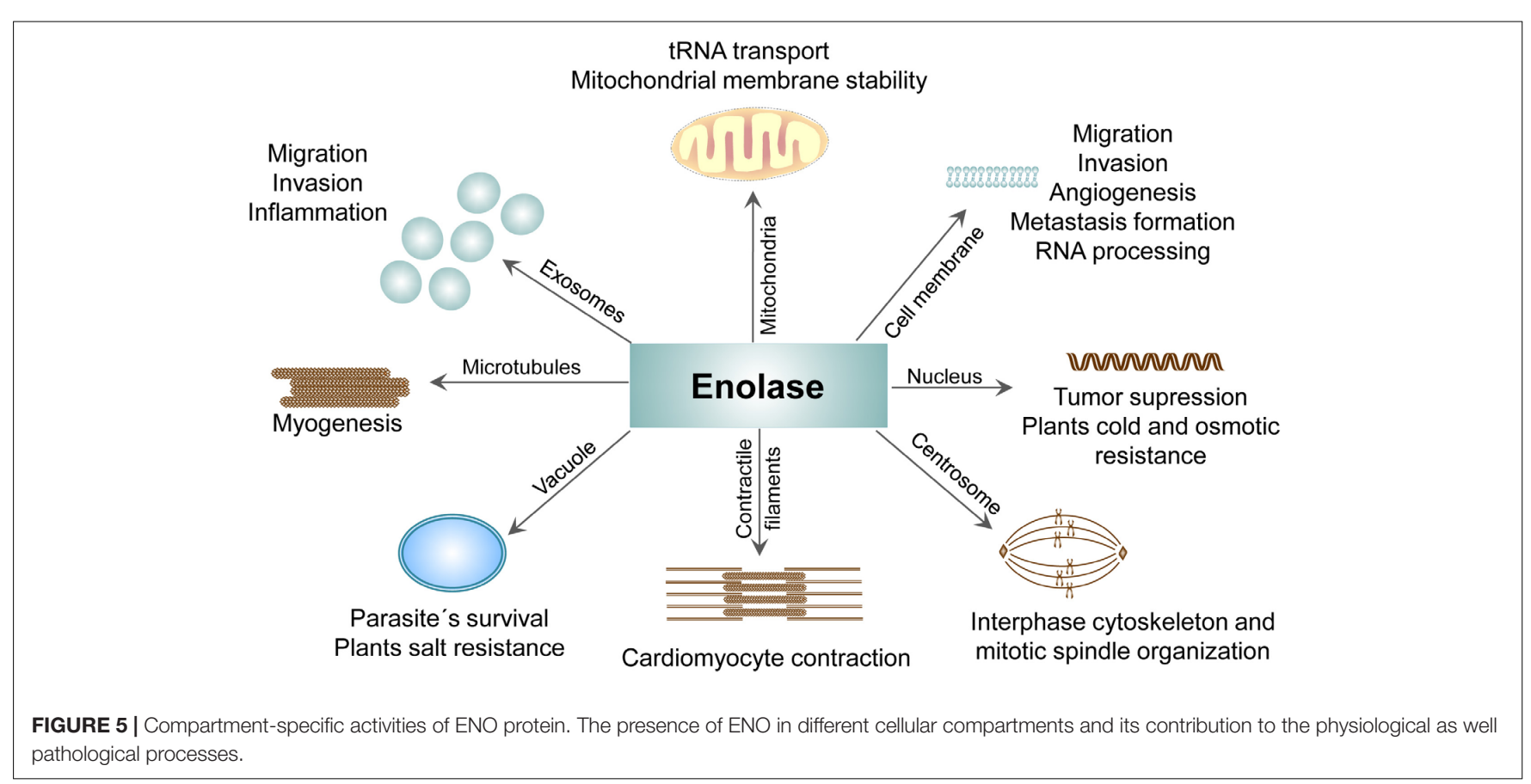


entry were found to be crucial for this process (Didiasova et al., 2015). In addition, we observed that exposure of cancer cells to LPS triggers protein arginine methyltransferase 5 (PRMT5)-mediated monomethylation of arginine 50 in ENO-1 (Zakrzewicz et al., 2018) and thus enhances cell surface expression of this protein. Interestingly, several other ENO-1 PTMs, such as ubiqitination, acetylation and phosphorylation were reported too (Pal-Bhowmick et al., 2007b; Foth et al., 2008; Shevade et al., 2013) and ENO-1 ubiquitination was found to direct ENO-1 to vacuoles. In addition, we explored that ENO-1 interaction with caveolin-1 and annexin-2 promotes ENO-1 translocation to specialized subset of lipid rafts called caveolae and thus its transport to the extracellular space (Zakrzewicz et al., 2014). Although it is not clear how these single mechanisms coordinate the process of ENO-1 exteriorization, it is tempting to speculate that the initial increase of intracellular calcium induced by LPS triggers ENO-1 methylation, which works as a sorting signal and marks ENO-1 designated to the cell membrane. Consequently, binding of ENO-1 to caveolin-1 and annexin-2 then facilitates the translocation of this enzyme to the extracellular space. However, the precise molecular mechanism regulating these steps needs to be further investigated.

As indicated above, ENO-1 is not only translocated to the cell surface but also released into the extracellular space either in the form of exosomes (Graner et al., 2009; Henderson and Azorsa, 2012; Didiasova et al., 2015) or as a soluble protein (Guillou et al., 2016). Exosomes are small vesicles that play a role in the intercellular communication and may influence behavior of target cells. We found that exosomes loaded with ENO-1 may enhance cancer cell migration and invasion (Didiasova et al., 2015). Soluble ENO-1 was found in serum and synovial fluid of rheumatoid arthritis patients (Guillou et al., 2016) and in serum of patients suffering from lupus erythematosus (Hawro et al., 2015; Li et al., 2018), systemic sclerosis (Terrier et al., 2010; Mehra et al., 2013) and Alzheimert's disease (Castegna et al., 2002; Butterfield and Lange, 2009; Owen et al., 2009). In rheumatoid arthritis, ENO-1 was found to reattach to the cell surface of monocytes and stimulate their pro-inflammatory state by inducing the CD14-dependent TLR4 signaling (Guillou et al., 2016). Similar observations have been made in patients with a kidney stone disease. Here, it was proposed that ENO-1 secreted from renal tubular cells may attach not only to monocytes but also to calcium oxalate crystals, the constituents of kidney stones, thus promoting tissue invasion of monocytes and attachment of calcium oxalate crystals to ECM (Chiangjong and Thongboonkerd, 2016).

To sum up, not only surface-bound but also secreted ENO-1 displays strong PLG binding capacity and thus marked

\section{REFERENCES}

Almeida, L., Vanegas, G., Calcagno, M., Concepcion, J. L., and Avilan, L. (2004). Plasminogen interaction with Trypanosoma cruzi. Mem. Inst. Oswaldo Cruz 99, 63-67. doi: 10.1590/s0074-02762004000100011

Altenberg, B., and Greulich, K. O. (2004). Genes of glycolysis are ubiquitously overexpressed in 24 cancer classes. Genomics 84, 1014-1020. doi: 10.1016/j. ygeno.2004.08.010 impact on local extracellular proteolytic activity. Hence, targeting extracellular ENO-1 may be beneficial not only in the treatment of cancer patients, but also in infectious diseases caused by multiresistant strains and in chronic autoimmune diseases.

\section{CONCLUSION AND FINAL REMARKS}

The glycolytic enzyme ENO-1 displays highly plastic nature when it comes to its activities. ENO non-glycolytic functions such as cell surface plasminogen binding, maintenance of the mitochondrial membrane stability, transcriptional repressor activity in the nucleus, as well as chaperon and vacuole fusion activity in the cytoplasm imply that the localization of this enzyme determinates its action (Figure 5). Since the mechanistic aspects underlying ENO multitasking remain not understood, future studies are needed to explore the structural and molecular requirements driving ENO shuttling and thus its diverse activities. Nevertheless, the fact that ENO-1 handles high number of cellular processes indicates that ENO-1 targeted therapeutic approaches should be carefully considered. To avoid adverse effects related to the inhibition of the physiological activities of ENO-1 in healthy cells, therapies targeting pathological features of ENO-1 in diseased cells are urgently needed. Nanoparticles with cell-specific targeting may offer such a possibility. A recently published study documented a significant anti-tumor effect of ENO-1 targeted lipid nanoparticles in an animal model of prostate cancer (Wang et al., 2018), thus opening the door for the future clinical trials not only in tumor-related pathologies, but also in other diseases, such as diabetes and cardiac hypertrophy, where ENO-1 related abnormalities are observed as well.

\section{AUTHOR CONTRIBUTIONS}

MD conceived and wrote the manuscript. LS edited manuscript and provided valuable comments. MW revised the manuscript.

\section{FUNDING}

The study was funded by the German Research Foundation (SFBTR84, project A2 to MW; SFB 815, project A5; SFB 1039, project B2; SFB 1177, project C02; and SCHA 1082/6-1 to LS. The Else Kröner-Fresenius-Foundation (to MW), the Excellence Cluster "Cardiopulmonary System" (to MW and LS) and the German Center for Lung Research (to MW).

Baleva, M., Gowher, A., Kamenski, P., Tarassov, I., Entelis, N., and Masquida, B. (2015). A moonlighting human protein is involved in mitochondrial import of tRNA. Int. J. Mol. Sci. 16, 9354-9367. doi: 10.3390/ijms1605 9354

Bao, S., Guo, X., Yu, S., Ding, J., Tan, L., Zhang, F., et al. (2014). Mycoplasma synoviae enolase is a plasminogen/fibronectin binding protein. BMC Vet. Res. 10:223. doi: 10.1186/s12917-0140223-6 
Barkla, B. J., Vera-Estrella, R., Hernandez-Coronado, M., and Pantoja, O. (2009). Quantitative proteomics of the tonoplast reveals a role for glycolytic enzymes in salt tolerance. Plant Cell 21, 4044-4058. doi: 10.1105/tpc.109.069211

Bergmann, S., Rohde, M., Chhatwal, G. S., and Hammerschmidt, S. (2001). alpha-Enolase of Streptococcus pneumoniae is a plasmin(ogen)-binding protein displayed on the bacterial cell surface. Mol. Microbiol. 40, 1273-1287. doi: 10.1046/j.1365-2958.2001.02448.x

Bergmann, S., Schoenen, H., and Hammerschmidt, S. (2013). The interaction between bacterial enolase and plasminogen promotes adherence of Streptococcus pneumoniae to epithelial and endothelial cells. Int. J. Med. Microbiol. 303, 452-462. doi: 10.1016/j.ijmm.2013.06.002

Bhowmick, I. P., Kumar, N., Sharma, S., Coppens, I., and Jarori, G. K. (2009). Plasmodium falciparum enolase: stage-specific expression and sub-cellular localization. Malar. J. 8:179. doi: 10.1186/1475-2875-8-179

Brandina, I., Graham, J., Lemaitre-Guillier, C., Entelis, N., Krasheninnikov, I., Sweetlove, L., et al. (2006). Enolase takes part in a macromolecular complex associated to mitochondria in yeast. Biochim. Biophys. Acta 1757, 1217-1228. doi: 10.1016/j.bbabio.2006.07.001

Brewer, J. M. (1981). Yeast enolase: mechanism of activation by metal ions. CRC Crit. Rev. Biochem. 11, 209-254. doi: 10.3109/10409238109108702

Butterfield, D. A., and Lange, M. L. (2009). Multifunctional roles of enolase in Alzheimer's disease brain: beyond altered glucose metabolism. J. Neurochem. 111, 915-933. doi: 10.1111/j.1471-4159.2009.06397.x

Capello, M., Ferri-Borgogno, S., Riganti, C., Chattaragada, M. S., Principe, M., Roux, C., et al. (2016). Targeting the Warburg effect in cancer cells through ENO1 knockdown rescues oxidative phosphorylation and induces growth arrest. Oncotarget 7, 5598-5612. doi: 10.18632/oncotarget.6798

Cappello, P., Tomaino, B., Chiarle, R., Ceruti, P., Novarino, A., Castagnoli, C., et al. (2009). An integrated humoral and cellular response is elicited in pancreatic cancer by alpha-enolase, a novel pancreatic ductal adenocarcinoma-associated antigen. Int. J. Cancer 125, 639-648. doi: 10.1002/ijc.24355

Carvalho, C., Santos, R. X., Cardoso, S., Correia, S., Oliveira, P. J., Santos, M. S., et al. (2009). Doxorubicin: the good, the bad and the ugly effect. Curr. Med. Chem. 16, 3267-3285. doi: 10.2174/092986709788803312

Castegna, A., Aksenov, M., Thongboonkerd, V., Klein, J. B., Pierce, W. M., Booze, R., et al. (2002). Proteomic identification of oxidatively modified proteins in Alzheimer's disease brain. Part II: dihydropyrimidinase-related protein 2, alphaenolase and heat shock cognate 71. J. Neurochem. 82, 1524-1532. doi: 10.1046/ j.1471-4159.2002.01103.x

Chhatwal, G. S. (2002). Anchorless adhesins and invasins of Gram-positive bacteria: a new class of virulence factors. Trends Microbiol. 10, 205-208. doi: 10.1016/s0966-842x(02)02351-x

Chiangjong, W., and Thongboonkerd, V. (2016). Calcium oxalate crystals increased enolase-1 secretion from renal tubular cells that subsequently enhanced crystal and monocyte invasion through renal interstitium. Sci. Rep. 6:24064. doi: 10.1038/srep24064

Cho, H., Um, J., Lee, J. H., Kim, W. H., Kang, W. S., Kim, S. H., et al. (2017). ENOblock, a unique small molecule inhibitor of the non-glycolytic functions of enolase, alleviates the symptoms of type 2 diabetes. Sci. Rep. 7:44186. doi: $10.1038 /$ srep 44186

Dai, J., Zhou, Q., Chen, J., Rexius-Hall, M. L., Rehman, J., and Zhou, G. (2018). Alpha-enolase regulates the malignant phenotype of pulmonary artery smooth muscle cells via the AMPK-Akt pathway. Nat. Commun. 9:3850. doi: 10.1038/ s41467-018-06376-x

Dang, C. V. (2013). MYC, metabolism, cell growth, and tumorigenesis. Cold Spring Harb. Perspect. Med. 3:a014217. doi: 10.1101/cshperspect.a014217

Das, R., Burke, T., and Plow, E. F. (2007). Histone H2B as a functionally important plasminogen receptor on macrophages. Blood 110, 3763-3772. doi: 10.1182/ blood-2007-03-079392

Decker, B. L., and Wickner, W. T. (2006). Enolase activates homotypic vacuole fusion and protein transport to the vacuole in yeast. J. Biol. Chem. 281, 14523-14528. doi: 10.1074/jbc.M600911200

Derbise, A., Song, Y. P., Parikh, S., Fischetti, V. A., and Pancholi, V. (2004). Role of the C-terminal lysine residues of streptococcal surface enolase in Glu- and Lys-plasminogen-binding activities of group A streptococci. Infect. Immun. 72, 94-105. doi: 10.1128/iai.72.1.94-105.2004

Diaz-Ramos, A., Roig-Borrellas, A., Garcia-Melero, A., and Lopez-Alemany, R. (2012). alpha-Enolase, a multifunctional protein: its role on pathophysiological situations. J. Biomed. Biotechnol. 2012:156795. doi: 10.1155/2012/ 156795

Didiasova, M., Wujak, L., Wygrecka, M., and Zakrzewicz, D. (2014). From plasminogen to plasmin: role of plasminogen receptors in human cancer. Int. J. Mol. Sci. 15, 21229-21252. doi: 10.3390/ijms151121229

Didiasova, M., Zakrzewicz, D., Magdolen, V., Nagaraj, C., Balint, Z., Rohde, M., et al. (2015). STIM1/ORAI1-mediated $\mathrm{Ca}^{2+}$ Influx Regulates Enolase1 Exteriorization. J. Biol. Chem. 290, 11983-11999. doi: 10.1074/jbc.M114. 598425

Dutta, S., DasSarma, P., DasSarma, S., and Jarori, G. K. (2015). Immunogenicity and protective potential of a Plasmodium spp. enolase peptide displayed on archaeal gas vesicle nanoparticles. Malar. J. 14:406. doi: 10.1186/s12936-0150914-x

Dutta, S., Tewari, A., Balaji, C., Verma, R., Moitra, A., Yadav, M., et al. (2018). Strain-transcending neutralization of malaria parasite by antibodies against Plasmodium falciparum enolase. Malar. J. 17:304. doi: 10.1186/s12936-0182455-6

Entelis, N., Brandina, I., Kamenski, P., Krasheninnikov, I. A., Martin, R. P., and Tarassov, I. (2006). A glycolytic enzyme, enolase, is recruited as a cofactor of tRNA targeting toward mitochondria in Saccharomyces cerevisiae. Genes Dev. 20, 1609-1620. doi: 10.1101/gad.385706

Feo, S., Arcuri, D., Piddini, E., Passantino, R., and Giallongo, A. (2000). ENO1 gene product binds to the $\mathrm{c}$-myc promoter and acts as a transcriptional repressor: relationship with Myc promoter-binding protein 1 (MBP-1). FEBS Lett. 473, 47-52. doi: 10.1016/s0014-5793(00)01494-0

Floden, A. M., Watt, J. A., and Brissette, C. A. (2011). Borrelia burgdorferi enolase is a surface-exposed plasminogen binding protein. PLoS One 6:e27502. doi: 10.1371/journal.pone.0027502

Foth, B. J., Zhang, N., Mok, S., Preiser, P. R., and Bozdech, Z. (2008). Quantitative protein expression profiling reveals extensive post-transcriptional regulation and post-translational modifications in schizont-stage malaria parasites. Genome Biol. 9:R177. doi: 10.1186/gb-2008-9-12-r177

Fox, D., and Smulian, A. G. (2001). Plasminogen-binding activity of enolase in the opportunistic pathogen Pneumocystis carinii. Med. Mycol. 39, 495-507. doi: 10.1080/714031070

Funk, J., Schaarschmidt, B., Slesiona, S., Hallstrom, T., Horn, U., and Brock, M. (2016). The glycolytic enzyme enolase represents a plasminogen-binding protein on the surface of a wide variety of medically important fungal species. Int. J. Med. Microbiol. 306, 59-68. doi: 10.1016/j.ijmm.2015.11.005

Gao, S., Li, H., Cai, Y., Ye, J. T., Liu, Z. P., Lu, J., et al. (2014). Mitochondrial binding of alpha-enolase stabilizes mitochondrial membrane: its role in doxorubicininduced cardiomyocyte apoptosis. Arch. Biochem. Biophys. 542, 46-55. doi: 10.1016/j.abb.2013.12.008

Gao, S., Li, H., Feng, X. J., Li, M., Liu, Z. P., Cai, Y., et al. (2015). alpha-Enolase plays a catalytically independent role in doxorubicin-induced cardiomyocyte apoptosis and mitochondrial dysfunction. J. Mol. Cell. Cardiol. 79, 92-103. doi: 10.1016/j.yjmcc.2014.11.007

Ghosh, A. K., Steele, R., and Ray, R. B. (2005a). c-myc Promoter-binding protein 1 (MBP-1) regulates prostate cancer cell growth by inhibiting MAPK pathway. J. Biol. Chem. 280, 14325-14330. doi: 10.1074/jbc.M413313200

Ghosh, A. K., Steele, R., and Ray, R. B. (2005b). Carboxyl-terminal repressor domain of MBP-1 is sufficient for regression of prostate tumor growth in nude mice. Cancer Res. 65, 718-721.

Giege, P., Heazlewood, J. L., Roessner-Tunali, U., Millar, A. H., Fernie, A. R., Leaver, C. J., et al. (2003). Enzymes of glycolysis are functionally associated with the mitochondrion in Arabidopsis cells. Plant Cell 15, 2140-2151. doi: 10.1105/tpc.012500

Graner, M. W., Alzate, O., Dechkovskaia, A. M., Keene, J. D., Sampson, J. H., Mitchell, D. A., et al. (2009). Proteomic and immunologic analyses of brain tumor exosomes. FASEB J. 23, 1541-1557. doi: 10.1096/fj.08-122184

Guillou, C., Freret, M., Fondard, E., Derambure, C., Avenel, G., Golinski, M. L., et al. (2016). Soluble alpha-enolase activates monocytes by CD14-dependent TLR4 signalling pathway and exhibits a dual function. Sci. Rep. 6:23796. doi: $10.1038 /$ srep23796

Haque, A., Polcyn, R., Matzelle, D., and Banik, N. L. (2018). New Insights into the Role of Neuron-Specific Enolase in Neuro-Inflammation, Neurodegeneration, and Neuroprotection. Brain Sci. 8:33. doi: 10.3390/brainsci802 0033 
Hawro, T., Bogucki, A., Krupinska-Kun, M., Maurer, M., and Wozniacka, A. (2015). Serum neuron specific enolase - a novel indicator for neuropsychiatric systemic lupus erythematosus? Lupus 24, 1492-1497. doi: $10.1177 / 0961203315593818$

Henderson, M. C., and Azorsa, D. O. (2012). The genomic and proteomic content of cancer cell-derived exosomes. Front. Oncol. 2:38. doi: 10.3389/fonc.2012. 00038

Hsiao, K. C., Shih, N. Y., Fang, H. L., Huang, T. S., Kuo, C. C., Chu, P. Y., et al. (2013). Surface alpha-enolase promotes extracellular matrix degradation and tumor metastasis and represents a new therapeutic target. PLoS One 8:e69354. doi: 10.1371/journal.pone.0069354

Hsu, K. W., Hsieh, R. H., Lee, Y. H., Chao, C. H., Wu, K. J., Tseng, M. J., et al. (2008). The activated Notch1 receptor cooperates with alpha-enolase and MBP1 in modulating c-myc activity. Mol. Cell. Biol. 28, 4829-4842. doi: 10.1128/ MCB.00175-08

Hsu, K. W., Hsieh, R. H., Wu, C. W., Chi, C. W., Lee, Y. H., Kuo, M. L., et al. (2009). MBP-1 suppresses growth and metastasis of gastric cancer cells through COX-2. Mol. Biol. Cell 20, 5127-5137. doi: 10.1091/mbc.E09-05-0386

Huang, L. E. (2008). Carrot and stick: HIF-alpha engages c-Myc in hypoxic adaptation. Cell Death Differ. 15, 672-677. doi: 10.1038/sj.cdd.4402302

Iida, H., and Yahara, I. (1985). Yeast heat-shock protein of $\mathrm{Mr} 48,000$ is an isoprotein of enolase. Int. J. Sci. 315, 688-690. doi: 10.1038/315688a0

Ji, H., Wang, J., Guo, J., Li, Y., Lian, S., Guo, W., et al. (2016). Progress in the biological function of alpha-enolase. Anim. Nutr. 2, 12-17. doi: 10.1016/j.aninu. 2016.02.005

Johnstone, S. A., Waisman, D. M., and Rattner, J. B. (1992). Enolase is present at the centrosome of HeLa cells. Exp. Cell Res. 202, 458-463. doi: 10.1016/00144827(92)90099-t

Jung, D. W., Kim, W. H., Park, S. H., Lee, J., Kim, J., Su, D., et al. (2013). A unique small molecule inhibitor of enolase clarifies its role in fundamental biological processes. ACS Chem. Biol. 8, 1271-1282. doi: 10.1021/cb300687k

Kanda, T., Raychoudhuri, A., Steele, R., Sagartz, J. E., West, C., and Ray, R. B. (2009). MBP-1 inhibits breast cancer growth and metastasis in immunocompetent mice. Cancer Res. 69, 9354-9359. doi: 10.1158/0008-5472. CAN-09-2974

Keller, A., Peltzer, J., Carpentier, G., Horvath, I., Olah, J., Duchesnay, A., et al. (2007). Interactions of enolase isoforms with tubulin and microtubules during myogenesis. Biochim. Biophys. Acta 1770, 919-926. doi: 10.1016/j.bbagen.2007. 01.015

Kim, I., Rodriguez-Enriquez, S., and Lemasters, J. J. (2007). Selective degradation of mitochondria by mitophagy. Arch. Biochem. Biophys. 462, 245-253. doi: 10.1016/j.abb.2007.03.034

Kinloch, A., Tatzer, V., Wait, R., Peston, D., Lundberg, K., Donatien, P., et al. (2005). Identification of citrullinated alpha-enolase as a candidate autoantigen in rheumatoid arthritis. Arthritis Res. Ther. 7, R1421-R1429. doi: 10.1186/ $\operatorname{ar} 1845$

Knaust, A., Weber, M. V., Hammerschmidt, S., Bergmann, S., Frosch, M., and Kurzai, O. (2007). Cytosolic proteins contribute to surface plasminogen recruitment of Neisseria meningitidis. J. Bacteriol. 189, 3246-3255. doi: 10.1128/ JB.01966-06

Lee, H., Guo, Y., Ohta, M., Xiong, L., Stevenson, B., and Zhu, J. K. (2002). LOS2, a genetic locus required for cold-responsive gene transcription encodes a bi-functional enolase. EMBO J. 21, 2692-2702. doi: 10.1093/emboj/21.11. 2692

Leroy, A., Vanzo, N. F., Sousa, S., Dreyfus, M., and Carpousis, A. J. (2002). Function in Escherichia coli of the non-catalytic part of RNase E: role in the degradation of ribosome-free mRNA. Mol. Microbiol. 45, 1231-1243. doi: 10.1046/j.13652958.2002.03104.x

Li, J., Yan, M., Zhang, Y., Xie, M., Yan, L., and Chen, J. (2015). Serum neuronspecific enolase is elevated as a novel indicator of diabetic retinopathy including macular oedema. Diabet. Med. 32, 102-107. doi: 10.1111/dme.12597

Li, J., Zhang, H., Xie, M., Yan, L., Chen, J., and Wang, H. (2013). NSE, a potential biomarker, is closely connected to diabetic peripheral neuropathy. Diabetes Care 36, 3405-3410. doi: 10.2337/dc13-0590

Li, M., Li, J., Wang, J., Li, Y., and Yang, P. (2018). Serum level of anti-alphaenolase antibody in untreated systemic lupus erythematosus patients correlates with 24-hour urine protein and D-dimer. Lupus 27, 139-142. doi: 10.1177/ 0961203317721752
Liou, G. G., Jane, W. N., Cohen, S. N., Lin, N. S., and Lin-Chao, S. (2001). RNA degradosomes exist in vivo in Escherichia coli as multicomponent complexes associated with the cytoplasmic membrane via the $\mathrm{N}$-terminal region of ribonuclease E. Proc. Natl. Acad. Sci. U.S.A. 98, 63-68. doi: 10.1073/pnas. 011535498

Lo Presti, M., Ferro, A., Contino, F., Mazzarella, C., Sbacchi, S., Roz, E., et al. (2010). Myc promoter-binding protein-1 (MBP-1) is a novel potential prognostic marker in invasive ductal breast carcinoma. PLoS One 5:e12961. doi: 10.1371/ journal.pone.0012961

Luo, Q., Jiang, L., Chen, G., Feng, Y., Lv, Q., Zhang, C., et al. (2011). Constitutive heat shock protein 70 interacts with alpha-enolase and protects cardiomyocytes against oxidative stress. Free Radic. Res. 45, 1355-1365. doi: 10.3109/10715762. 2011.627330

Marangos, P. J., Parma, A. M., and Goodwin, F. K. (1978). Functional properties of neuronal and glial isoenzymes of brain enolase. J. Neurochem. 31, 727-732. doi: 10.1111/j.1471-4159.1978.tb07847.x

Maranto, C., Perconti, G., Contino, F., Rubino, P., Feo, S., and Giallongo, A. (2015). Cellular stress induces cap-independent alpha-enolase/MBP-1 translation. FEBS Lett. 589, 2110-2116. doi: 10.1016/j.febslet.2015.06.030

Martin, R. P., Schneller, J. M., Stahl, A. J., and Dirheimer, G. (1979). Import of nuclear deoxyribonucleic acid coded lysine-accepting transfer ribonucleic acid (anticodon C-U-U) into yeast mitochondria. Biochemistry 18, 4600-4605. doi: 10.1021/bi00588a021

Mehra, S., Walker, J., Patterson, K., and Fritzler, M. J. (2013). Autoantibodies in systemic sclerosis. Autoimmun. Rev. 12, 340-354. doi: 10.1016/j.autrev.2012. 05.011

Mikuriya, K., Kuramitsu, Y., Ryozawa, S., Fujimoto, M., Mori, S., Oka, M., et al. (2007). Expression of glycolytic enzymes is increased in pancreatic cancerous tissues as evidenced by proteomic profiling by two-dimensional electrophoresis and liquid chromatography-mass spectrometry/mass spectrometry. Int. J. Oncol. 30, 849-855.

Miles, L. A., Dahlberg, C. M., Plescia, J., Felez, J., Kato, K., and Plow, E. F. (1991). Role of cell-surface lysines in plasminogen binding to cells: identification of alpha-enolase as a candidate plasminogen receptor. Biochemistry 30, 1682-1691. doi: 10.1021/bi00220a034

Mizukami, Y., Iwamatsu, A., Aki, T., Kimura, M., Nakamura, K., Nao, T., et al. (2004). ERK1/2 regulates intracellular ATP levels through alpha-enolase expression in cardiomyocytes exposed to ischemic hypoxia and reoxygenation. J. Biol. Chem. 279, 50120-50131. doi: 10.1074/jbc.M402299200

Montes, A., Dieguez-Gonzalez, R., Perez-Pampin, E., Calaza, M., Mera-Varela, A. Gomez-Reino, J. J., et al. (2011). Particular association of clinical and genetic features with autoimmunity to citrullinated alpha-enolase in rheumatoid arthritis. Arthritis Rheum. 63, 654-661. doi: 10.1002/art.30186

Morita, T., Kawamoto, H., Mizota, T., Inada, T., and Aiba, H. (2004). Enolase in the RNA degradosome plays a crucial role in the rapid decay of glucose transporter mRNA in the response to phosphosugar stress in Escherichia coli. Mol. Microbiol. 54, 1063-1075. doi: 10.1111/j.1365-2958.2004.04329.x

Nogueira, S. V., Fonseca, F. L., Rodrigues, M. L., Mundodi, V., Abi-Chacra, E. A., Winters, M. S., et al. (2010). Paracoccidioides brasiliensis enolase is a surface protein that binds plasminogen and mediates interaction of yeast forms with host cells. Infect. Immun. 78, 4040-4050. doi: 10.1128/IAI.00221-10

O'Mullane, M. J., and Baker, M. S. (1999). Elevated plasminogen receptor expression occurs as a degradative phase event in cellular apoptosis. Immunol. Cell Biol. 77, 249-255. doi: 10.1046/j.1440-1711.1999.00823.x

Owen, J. B., Di Domenico, F., Sultana, R., Perluigi, M., Cini, C., Pierce, W. M., et al. (2009). Proteomics-determined differences in the concanavalin-Afractionated proteome of hippocampus and inferior parietal lobule in subjects with Alzheimer's disease and mild cognitive impairment: implications for progression of AD. J. Proteome Res. 8, 471-482. doi: 10.1021/pr800667a

Pal-Bhowmick, I., Mehta, M., Coppens, I., Sharma, S., and Jarori, G. K. (2007a). Protective properties and surface localization of Plasmodium falciparum enolase. Infect. Immun. 75, 5500-5508. doi: 10.1128/IAI.00551-07

Pal-Bhowmick, I., Vora, H. K., and Jarori, G. K. (2007b). Sub-cellular localization and post-translational modifications of the Plasmodium yoelit enolase suggest moonlighting functions. Malar. J. 6:45. doi: 10.1186/14752875-6-45

Pancholi, V. (2001). Multifunctional alpha-enolase: its role in diseases. Cell. Mol. Life Sci. 58, 902-920. doi: 10.1007/pl00000910 
Pancholi, V., and Fischetti, V. A. (1998). alpha-enolase, a novel strong plasmin(ogen) binding protein on the surface of pathogenic streptococci. J. Biol. Chem. 273, 14503-14515. doi: 10.1074/jbc.273.23.14503

Peng, B., Huang, X., Nakayasu, E. S., Petersen, J. R., Qiu, S., Almeida, I. C., et al. (2013). Using immunoproteomics to identify alpha-enolase as an autoantigen in liver fibrosis. J. Proteome Res. 12, 1789-1796. doi: 10.1021/pr301 1342

Perconti, G., Ferro, A., Amato, F., Rubino, P., Randazzo, D., Wolff, T., et al. (2007). The kelch protein NS1-BP interacts with alpha-enolase/MBP-1 and is involved in c-Myc gene transcriptional control. Biochim. Biophys. Acta 1773, 1774-1785. doi: 10.1016/j.bbamcr.2007.09.002

Perconti, G., Maranto, C., Romancino, D. P., Rubino, P., Feo, S., Bongiovanni, A., et al. (2017). Pro-invasive stimuli and the interacting protein Hsp70 favour the route of alpha-enolase to the cell surface. Sci. Rep. 7:3841. doi: 10.1038/s41598017-04185-8

Petrak, J., Ivanek, R., Toman, O., Cmejla, R., Cmejlova, J., Vyoral, D., et al. (2008). Deja vu in proteomics. A hit parade of repeatedly identified differentially expressed proteins. Proteomics 8, 1744-1749. doi: 10.1002/pmic.200700919

Plow, E. F., and Das, R. (2009). Enolase-1 as a plasminogen receptor. Blood 113, 5371-5372. doi: 10.1182/blood-2009-03-208546

Principe, M., Ceruti, P., Shih, N. Y., Chattaragada, M. S., Rolla, S., Conti, L., et al. (2015). Targeting of surface alpha-enolase inhibits the invasiveness of pancreatic cancer cells. Oncotarget 6, 11098-11113. doi: 10.18632/oncotarget. 3572

Qin, J., Chai, G., Brewer, J. M., Lovelace, L. L., and Lebioda, L. (2012). Structures of asymmetric complexes of human neuron specific enolase with resolved substrate and product and an analogous complex with two inhibitors indicate subunit interaction and inhibitor cooperativity. J. Inorg. Biochem. 111, 187-194. doi: 10.1016/j.jinorgbio.2012.02.011

Ray, R. B., Steele, R., Seftor, E., and Hendrix, M. (1995). Human breast carcinoma cells transfected with the gene encoding a c-myc promoter-binding protein (MBP-1) inhibits tumors in nude mice. Cancer Res. 55, 3747-3751.

Redlitz, A., Fowler, B. J., Plow, E. F., and Miles, L. A. (1995). The role of an enolase-related molecule in plasminogen binding to cells. Eur. J. Biochem. 227, 407-415.

Rinehart, J., Krett, B., Rubio, M. A., Alfonzo, J. D., and Soll, D. (2005). Saccharomyces cerevisiae imports the cytosolic pathway for Gln-tRNA synthesis into the mitochondrion. Genes Dev. 19, 583-592. doi: 10.1101/gad.126 9305

Rotin, D., Staub, O., and Haguenauer-Tsapis, R. (2000). Ubiquitination and endocytosis of plasma membrane proteins: role of Nedd4/Rsp5p family of ubiquitin-protein ligases. J. Membr. Biol. 176, 1-17.

Sedoris, K. C., Thomas, S. D., and Miller, D. M. (2007). c-myc promoter binding protein regulates the cellular response to an altered glucose concentration. Biochemistry 46, 8659-8668. doi: 10.1021/bi7003558

Sedoris, K. C., Thomas, S. D., and Miller, D. M. (2010). Hypoxia induces differential translation of enolase/MBP-1. BMC Cancer 10:157. doi: 10.1186/1471-240710-157

Sha, J., Erova, T. E., Alyea, R. A., Wang, S., Olano, J. P., Pancholi, V., et al. (2009). Surface-expressed enolase contributes to the pathogenesis of clinical isolate SSU of Aeromonas hydrophila. J. Bacteriol. 191, 3095-3107. doi: 10.1128/JB. 00005-09

Sharma, S., Jadli, M., Singh, A., Arora, K., and Malhotra, P. (2014). A secretory multifunctional serine protease, DegP of Plasmodium falciparum, plays an important role in thermo-oxidative stress, parasite growth and development. FEBS J. 281, 1679-1699. doi: 10.1111/febs.12732

Shevade, S., Jindal, N., Dutta, S., and Jarori, G. K. (2013). Food vacuole associated enolase in plasmodium undergoes multiple post-translational modifications: evidence for atypical ubiquitination. PLoS One 8:e72687. doi: 10.1371/journal. pone. 0072687

Subramanian, A., and Miller, D. M. (2000). Structural analysis of alpha-enolase. Mapping the functional domains involved in down-regulation of the c-myc protooncogene. J. Biol. Chem. 275, 5958-5965.

Tamarit, J., Cabiscol, E., and Ros, J. (1998). Identification of the major oxidatively damaged proteins in Escherichia coli cells exposed to oxidative stress. J. Biol. Chem. 273, 3027-3032.
Tarassov, I., Entelis, N., and Martin, R. P. (1995a). An intact protein translocating machinery is required for mitochondrial import of a yeast cytoplasmic tRNA. J. Mol. Biol. 245, 315-323. doi: 10.1006/jmbi.19 94.0026

Tarassov, I., Entelis, N., and Martin, R. P. (1995b). Mitochondrial import of a cytoplasmic lysine-tRNA in yeast is mediated by cooperation of cytoplasmic and mitochondrial lysyl-tRNA synthetases. EMBO J. 14, 3461-3471.

Terrier, B., Tamby, M. C., Camoin, L., Guilpain, P., Berezne, A., Tamas, N., et al. (2010). Antifibroblast antibodies from systemic sclerosis patients bind to \{alpha\}-enolase and are associated with interstitial lung disease. Ann. Rheum. Dis. 69, 428-433. doi: 10.1136/ard.2008.104299

Ucker, D. S., Jain, M. R., Pattabiraman, G., Palasiewicz, K., Birge, R. B., and Li, H. (2012). Externalized glycolytic enzymes are novel, conserved, and early biomarkers of apoptosis. J. Biol. Chem. 287, 10325-10343. doi: 10.1074/jbc. M111.314971

Vander Heiden, M. G., Cantley, L. C., and Thompson, C. B. (2009). Understanding the Warburg effect: the metabolic requirements of cell proliferation. Science 324, 1029-1033. doi: 10.1126/science.11 60809

Vanegas, G., Quinones, W., Carrasco-Lopez, C., Concepcion, J. L., Albericio, F., and Avilan, L. (2007). Enolase as a plasminogen binding protein in Leishmania mexicana. Parasitol. Res. 101, 1511-1516. doi: 10.1007/s00436-007-0668-7

Wang, L., Qu, M., Huang, S., Fu, Y., Yang, L., He, S., et al. (2018). A novel alphaenolase-targeted drug delivery system for high efficacy prostate cancer therapy. Nanoscale 10, 13673-13683. doi: 10.1039/c8nr03297a

Wiederhold, E., Gandhi, T., Permentier, H. P., Breitling, R., Poolman, B., and Slotboom, D. J. (2009). The yeast vacuolar membrane proteome. Mol. Cell. Proteomics 8, 380-392. doi: 10.1074/mcp.M800372-MCP200

Wilkins, J. C., Homer, K. A., and Beighton, D. (2002). Analysis of Streptococcus mutans proteins modulated by culture under acidic conditions. Appl. Environ. Microbiol. 68, 2382-2390.

Wold, F., and Ballou, C. E. (1957a). Studies on the enzyme enolase. I. Equilibrium studies. J. Biol. Chem. 227, 301-312.

Wold, F., and Ballou, C. E. (1957b). Studies on the enzyme enolase. II. Kinetic studies. J. Biol. Chem. 227, 313-328.

Wygrecka, M., Marsh, L. M., Morty, R. E., Henneke, I., Guenther, A., Lohmeyer, J., et al. (2009). Enolase-1 promotes plasminogen-mediated recruitment of monocytes to the acutely inflamed lung. Blood 113, 5588-5598. doi: 10.1182/ blood-2008-08-170837

Zakrzewicz, D., Bergmann, S., Didiasova, M., Giaimo, B. D., Borggrefe, T., Mieth, M., et al. (2016). Host-derived extracellular RNA promotes adhesion of Streptococcus pneumoniae to endothelial and epithelial cells. Sci. Rep. 6:37758. doi: $10.1038 /$ srep 37758

Zakrzewicz, D., Didiasova, M., Kruger, M., Giaimo, B. D., Borggrefe, T., Mieth, M., et al. (2018). Protein arginine methyltransferase 5 mediates enolase- 1 cell surface trafficking in human lung adenocarcinoma cells. Biochim Biophys Acta Mol. Basis Dis. 1864(5 Pt A), 1816-1827. doi: 10.1016/j.bbadis.2018.02.021

Zakrzewicz, D., Didiasova, M., Zakrzewicz, A., Hocke, A. C., Uhle, F., Markart, P., et al. (2014). The interaction of enolase-1 with caveolae-associated proteins regulates its subcellular localization. Biochem. J. 460, 295-307. doi: 10.1042/ BJ20130945

Zhang, B., Wang, Z., Deng, B., Wu, X., Liu, J., and Feng, X. (2013). Identification of Enolase 1 and Thrombospondin-1 as serum biomarkers in HBV hepatic fibrosis by proteomics. Proteome Sci. 11:30. doi: 10.1186/1477-5956-11-30

Conflict of Interest Statement: The authors declare that the research was conducted in the absence of any commercial or financial relationships that could be construed as a potential conflict of interest.

Copyright (c) 2019 Didiasova, Schaefer and Wygrecka. This is an open-access article distributed under the terms of the Creative Commons Attribution License (CC BY). The use, distribution or reproduction in other forums is permitted, provided the original author(s) and the copyright owner(s) are credited and that the original publication in this journal is cited, in accordance with accepted academic practice. No use, distribution or reproduction is permitted which does not comply with these terms. 